\title{
FUZZY CONTROLLED DTC FED BY A FOUR SWITCH INVERTER FOR INDUCTION MOTOR
}

\author{
Meenu Mary Behanan ${ }^{1}$, Prathibha P.K ${ }^{2}$ \\ ${ }^{1}$ PG Scholar, Dept of EEE, Rajagiri School of Engineering and Technology, Kakkanad, Kerala,India, \\ meenu7447@gmail.com \\ ${ }^{2}$ Asst. Professor,Dept of EEE, Rajagiri School of Engineering and Technology, Kakkanad, Kerala, India, \\ prathibhapk@gmail.com
}

\begin{abstract}
Direct Torque Control of induction motor fed drives has become popular and widely used in industries due to fast and good torque response. Induction motors (IM) are simple in construction and are less sensitive to the motor parameters compared to other vector control methods. The conventional DTC is based on flux and torque hysteresis controllers. Induction motor is fed from a Four Switch Inverter generating the voltage vectors of the Six Switch Inverter by reconfiguration. Applying the most optimized voltage vector that produce fastest dynamic torque response during transient states. Fuzzy logic concept is a most efficient artificial integilence method which has high application in electric motor drives. A method to achieve fastest dynamic performance by modifying the two leg inverter fed DTC of induction motor based on Fuzzy Logic Concept is used here. This paper presents a rule-based fuzzy logic controller scheme designed and applied for the speed control of an induction motor fed from a four switch three phase inverter emulating the six switch three phase inverter. Due to the usage of the Fuzzy logic concept, the reliability, efficiency and performance of ac drive increases. Initial torque peak and torque ripple are minimized in the four switch three phase inverter based DTC using Fuzzy Logic.
\end{abstract}

Key Words: Direct Torque Control, Four Switch/Six Switch Three Phase Inverter, Fuzzy Logic, Induction motor(IM).

\section{INTRODUCTION}

From past decades DC motors are used for variable speed application due to an advantage that its torque and flux could be independently controlled by the field and armature current. But, DC motors have several disadvantages such as high cost, with brushes and commutator frequent maintenance problem and higher rotor inertia, cannot be operated in explosive environments. AC motors do not have the disadvantages of DC machines .In that Induction motors are widely used because of its inherent properties. IM are often termed the Workhorse of the Industry.

In normal reference frames, the torque and flux of an induction motor are coupled together and hence independent control becomes difficult. Rapid advancement in high-power semiconductor devices such as MOSFETs and IGBTs and high speed digital signal processing enables decoupling of torque and flux giving rise to high performance of drive. The IM control techniques are mainly classified as two: Scalar Controls and Vector Controls as shown in Fig 1. Both controls aims to have efficient motor torque and flux control regardless load parameter and motor variations. In scalar based control, the frequency and magnitude of voltage is controlled, where as in vector based control, the instantaneous position as well as the frequency and magnitude of voltage, current and flux linkage space vectors are controlled. For high performance AC Drives FOC (Field Oriented Control and DTC (Direct Torque Control) are the two popular vector control methods. Comparing with the FOC technique, DTC can provide less complexity with extremely good dynamic response with simple structure.

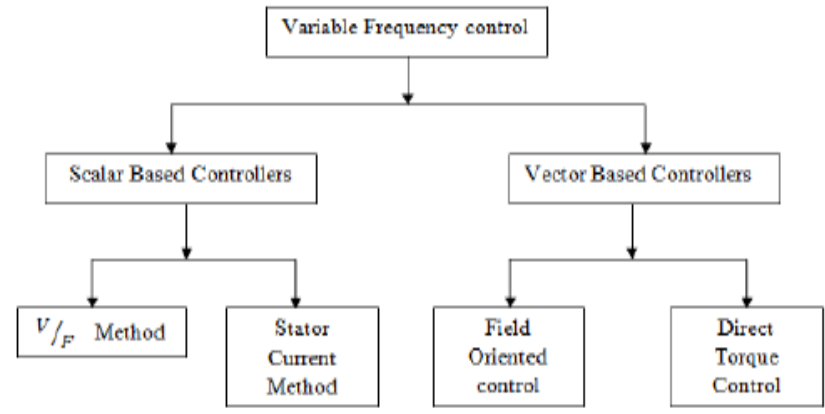

Fig 1. Induction motor control classifications

The first DTC strategy introduced in 1980s by Takahashi involves a simple and efficient control scheme for real time implementation [7]. Since, several investigations are carried out to improve the performance and efficiency of the original DTC scheme [6]. The main drawbacks of the conventional DTC were the variable switching frequency and high torque ripples. Hence investigations are carried out in areas of reduction of high torque ripple and uncontrolled switching frequency which results improvement of several DTC schemes have been proposed so far as in .

To eliminate these disadvantages and kept basic control rules of classical DTC, a new developed control technique was introduced with space vector modulator (DTC-SVM). In this method instead of a hysteresis controller used in classical DTC, the PI controllers and space vector modulator (SVM) are used[3]-[4].Reconfiguration of Six Switch Inverter into a four switch inverter to improve the reliability 
[5].This paper proposes a new Fuzzy logic into DTC strategy with a Four switch inverter fed to an induction motor. Fuzzy logic improves the overall performance of DTC controlled system [2]. Using an appropriate vector selection table and emulation of six switch inverter [1] an efficient method is implanted.

\section{FUZZY LOGIC BASED DIRECT TORQUE CONTROL OF FOUR SWITCH INVERTER}

DTC is an efficient control technique used in AC drive systems to achieve high performance torque control and flux control. Selection of the appropriate switching state for the inverter makes it possible.

\subsection{Basic Direct Torque Control}

The conventional DTC drive employs two level flux hysteresis controller and three level torque hysteresis controller and its outputs are flux error and torque error respectively. The system consists of flux and torque estimator, three phase six switch inverter and a voltage vector selection table. Estimation of the electromagnetic torque and motor's magnetic flux based on the measured voltage and current. Flux linkage is estimated by integrating the stator voltages. Torque is estimated as a cross product of measured motor current vector and estimated stator flux linkage vector. These estimated values are compared with the reference values.

Vector table has eight balanced voltage vectors in which six active voltage vectors and two zero voltage vectors. The active voltage vectors will have the same magnitude and are phase shifted each by an angle of $60^{\circ}$. According to the output of flux hysteresis controller $\mathrm{E} \varphi$, torque hysteresis controller $\mathrm{E} \tau$ and the angular displacement $\theta$ s the voltage vectors are selected The transistors are switched on and off of in such a way that either the torque and flux estimated is deviated from its reference value above a tolerance limit and will return as fast as possible.

\subsection{Four switch inverter fed DTC Strategy}

The implementation scheme of the Four switch inverter fed DTC strategy of an IM has the same layout as of the basic DTC strategy except that the Six switch inverter is reconfigured to a four switch by replacing one leg of the 3 leg inverter with a dc voltage.

A) Voltage Vectors of Four switch inverter: Out of the three phases ,two phases of the motor terminal is connected with the two leg of the inverter and the remaining phase is connected to the dc bus voltage midpoint. Compared to Six switch inverter the voltage vectors of the Four switch inverter has unbalanced amplitudes and phase shifted by an angle of $\frac{\pi}{2}$ But, vectors $V_{1}$ and $V_{3}$ have the equal amplitude with magnitude of $\frac{V_{d c}}{\sqrt{6}}$. The vectors $V_{2}$ and $V_{4}$ have the amplitude with a magnitude of $\frac{V_{d c}}{\sqrt{2}}$. The voltage vectors and switching states accordingly are illustrated in Fig. 2.

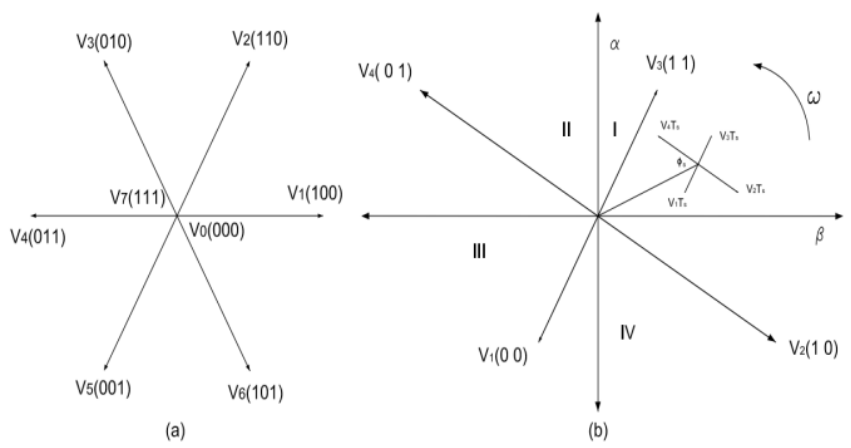

Fig.2 Voltage vectors and switching states of (a) Six switch and (b) Four switch

B) Generation of Balanced Voltage Vectors from Four switch inverter Voltage Vectors: The appropriate four voltage vectors for FSTPI are generated from the SSTPI voltage vectors itself.

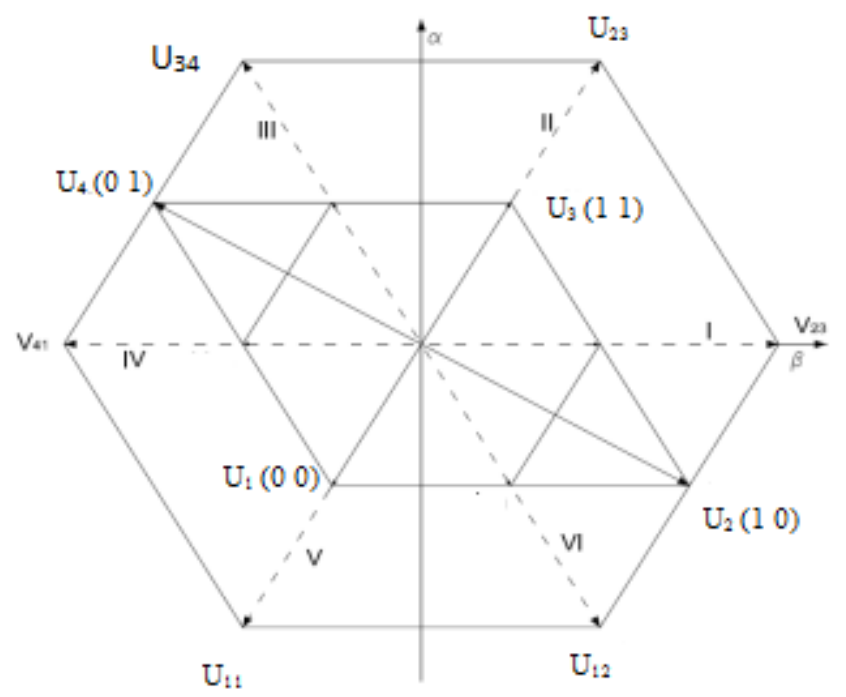

Fig. 3 Generation of Active Voltage Vectors

The six balanced voltage vectors of the Six switch inverter are generated using four unbalanced voltage vectors of the Four switch inverter. This generated voltage vectors will have the equal amplitude and angular shift of Six switch inverter.

C) Vector Selection Table: In order to reduce the torque ripple content in the DTC a new vector selection table is implemented. In the conventional system has a three level torque controller, it is replaced by a two level torque controller. To obtain each voltage vector of the six switch inverter appropriate combination of the unbalanced voltage vectors of the four switch inverter is applied. Each control combination $(\mathrm{E} \varphi, \mathrm{E} \tau)$ should be maintained during two sampling periods $\left(2 \mathrm{~T}_{\mathrm{s}}\right)$. Both the compounded and intrinsic voltage vectors are involved in sectors I, III, IV, and VI, while the sectors II and V, only the compounded voltage vectors are applied. ). Implemented voltage vector selection table is shown in Table I 
Table -1: Implemented voltage vector selection table

\begin{tabular}{|c|c|c|c|c|c|c|c|c|}
\hline $\mathrm{E} \varphi$ & \multicolumn{2}{|l|}{+1} & \multicolumn{2}{|l|}{+1} & \multicolumn{2}{|l|}{-1} & \multicolumn{2}{|l|}{-1} \\
\hline $\mathrm{E} \tau$ & \multicolumn{2}{|l|}{+1} & \multicolumn{2}{|l|}{-1} & \multicolumn{2}{|l|}{+1} & \multicolumn{2}{|l|}{-1} \\
\hline Period $T_{s}$ & $\mathrm{I}^{\mathrm{st}}$ & $\mathrm{II}^{\text {nd }}$ & $\mathrm{I}^{\mathrm{st}}$ & $\mathrm{II}^{\mathrm{nd}}$ & $\mathrm{I}^{\mathrm{st}}$ & $\mathrm{II}^{\text {nd }}$ & $\mathrm{I}^{\mathrm{st}}$ & $\mathrm{II}^{\mathrm{nd}}$ \\
\hline Sector I & \multicolumn{2}{|l|}{$\mathrm{U}_{3}$} & $\mathrm{U}_{1}$ & $\mathrm{U}_{2}$ & $\mathrm{U}_{3}$ & $\mathrm{U}_{4}$ & \multicolumn{2}{|l|}{$\mathrm{U}_{1}$} \\
\hline Sector II & $\mathrm{U}_{3}$ & $\mathrm{U}_{4}$ & $\mathrm{U}_{2}$ & $\mathrm{U}_{3}$ & $\mathrm{U}_{4}$ & $\mathrm{U}_{1}$ & $\mathrm{U}_{1}$ & $\mathrm{U}_{2}$ \\
\hline Sector III & $\mathrm{U}_{4}$ & $\mathrm{U}_{1}$ & \multicolumn{2}{|l|}{$\mathrm{U}_{3}$} & \multicolumn{2}{|l|}{$\mathrm{U}_{1}$} & $\mathrm{U}_{2}$ & $\mathrm{U}_{3}$ \\
\hline Sector IV & \multicolumn{2}{|l|}{$\mathrm{U}_{1}$} & $\mathrm{U}_{3}$ & $\mathrm{U}_{4}$ & $\mathrm{U}_{1}$ & $\mathrm{U}_{2}$ & \multicolumn{2}{|l|}{$\mathrm{U}_{3}$} \\
\hline Sector V & $\mathrm{U}_{1}$ & $\mathrm{U}_{2}$ & $\mathrm{U}_{4}$ & $\mathrm{U}_{1}$ & $\mathrm{U}_{2}$ & $\mathrm{U}_{3}$ & $\mathrm{U}_{3}$ & $\mathrm{U}_{4}$ \\
\hline Sector VI & $\mathrm{U}_{2}$ & $\mathrm{U}_{3}$ & \multicolumn{2}{|l|}{$\mathrm{U}_{1}$} & $\mathrm{U}_{3}$ & $\mathrm{U}_{4}$ & \multicolumn{2}{|l|}{$\mathrm{U}_{1}$} \\
\hline
\end{tabular}

\subsection{Fuzzy Logic Based DTC:}

Depending on an operator's experience an algorithm of nonmathematical decision making is called Fuzzy logic control. It is an intelligent controller and its design does not depend on accurate mathematical model of the system. Rather than exact or fixed reasoning the fuzzy logic deals with approximate many valued logic.

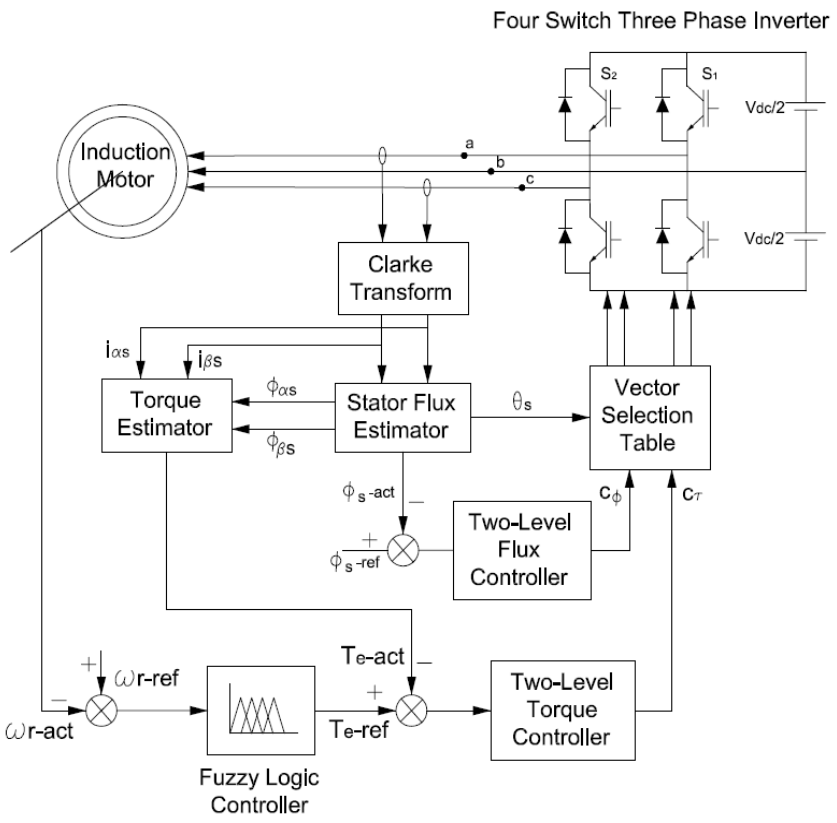

Fig. 4 Schematic Block Diagram of a Fuzzy Logic Based Four switch inverter -fed DTC

In a normal operating region when the torque is controlled, speed will be in control. FLC contains three basic parts: Fuzzification, Base rule, and Defuzzification. . This type of control strategy is well suited for non- linear systems.

The Fig 4 shows the schematic diagram of Four switch inverter fed to an induction motor using a fuzzy logic system. In the conventional DTC PI controllers are used for speed regulation. Here it is replaced by a fuzzy logic controller whose output is torque reference from the speed error values to maintain speed of the motor to be constant whenever the load varies. The speed error E and change of speed error DE is given as input to the fuzzy logic controller and the output is the torque reference. This reference value is compared with the actual torque and the torque error is generated. Triangular Membership functions were configured to represent the input in Fig 5 \& Fig 6 and output variables as shown in Fig. 7.

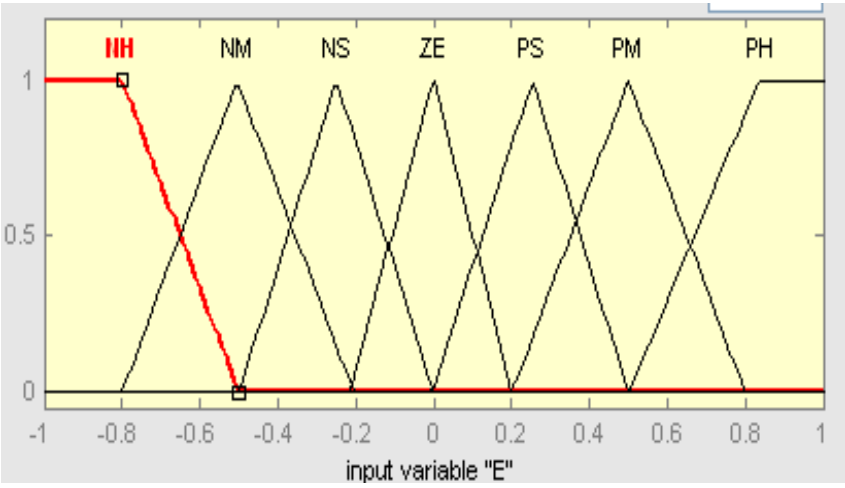

Fig. 5 Triangular membership functions of input

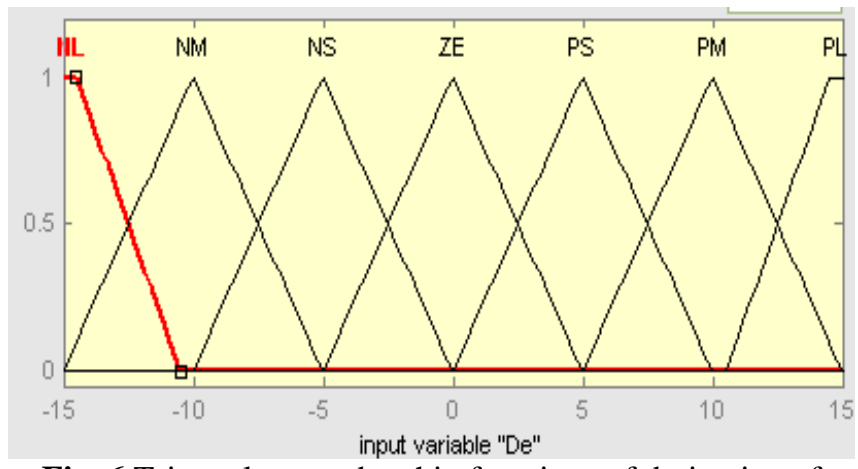

Fig. 6 Triangular membership functions of derivative of input

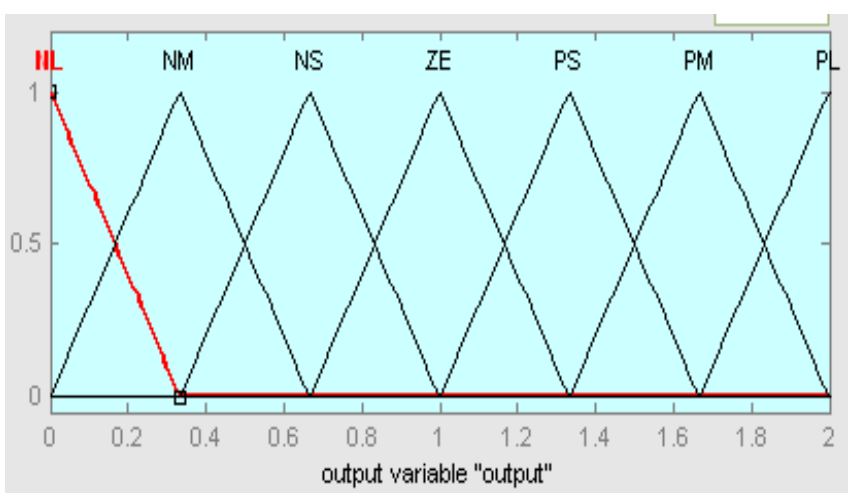

Fig. 7 Triangular membership functions of output

Consider the fuzzy speed control system, where the input signals are speed error (E) and derivative of speed error (DE) and the output is torque reference .They are fuzzified by assigning corresponding membership functions to each signal. The fuzzy sets are as zero (ZR), positive small(SP), positive medium(MP), positive high(HP), negative small(SN), negative medium(MN), negative high(HN). The universe of discourse of all the variables expressed in per unit values of between 0 and 1 .

Rule base consist of If Then fuzzy rule .It stores the data which defines the input and the output fuzzy sets. Here Mamdani method with seven membership functions. There are seven membership functions for $\mathrm{E}$ and $\mathrm{DE}$ whereas seven membership functions for the output. Hence there may be $7 * 7=49$ possible rules in the matrix. Table II shows the rule table for the speed controllerd.Defuzzification does the transformation of fuzzy sets to crisp values to continue the system process. 
Table II : Rule base for fuzzy logic

\begin{tabular}{|l|l|l|l|l|l|l|l|}
\hline E/DE & HN & MN & SN & ZR & SP & MP & HP \\
\hline HN & HP & MP & SP & SP & SP & MP & HP \\
\hline MN & HP & MP & SP & SP & SP & MP & HP \\
\hline SN & HP & MP & SP & ZR & SP & MP & HP \\
\hline ZR & HP & MP & SP & ZR & SP & MP & HP \\
\hline SP & HP & MP & SP & ZR & SP & MP & HP \\
\hline MP & HP & MP & SP & SP & SP & MP & HP \\
\hline HP & HP & MP & SP & SP & SP & MP & HP \\
\hline
\end{tabular}

\section{SIMULATION RESULTS}

A fuzzy controlled DTC fed to an Induction Motor from a four switch inverter is designed and simulated using MATLAB 10.The Simulink model of the system is shown in Fig 8. The model has three subsystems such as speed controller DTC and inverter subsystem. The four switch inverter is shown in Fig 9.

The output waveform of torque is shown in Fig 10 and speed is shown in Fig 11.Thw stator current is illustrated in Fig 12.

By analyzing the waveforms it is clear that the speed is constant and the torque and current ripple is reduced.

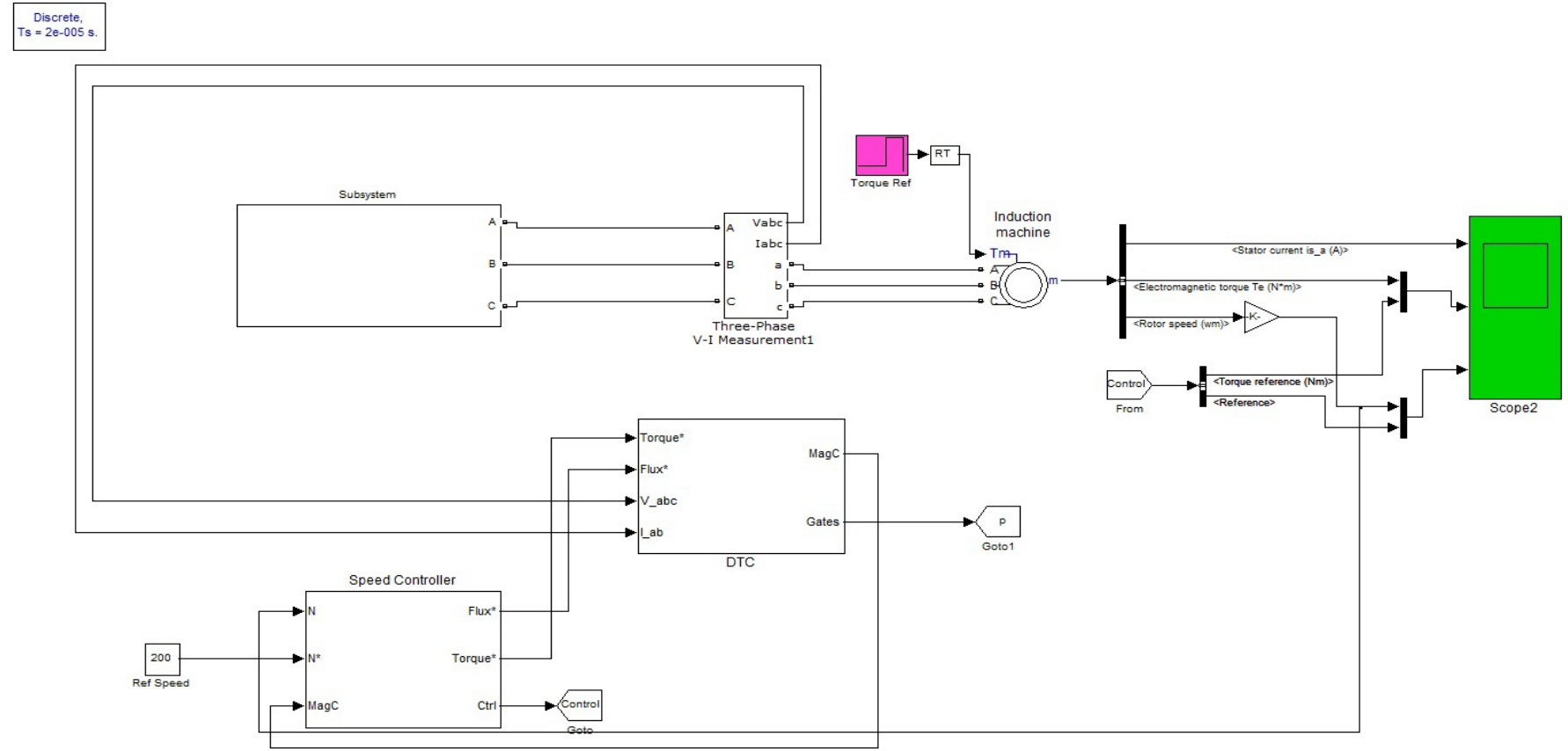

Fig 8. Simulation diagram for the Fuzzy controlled DTC of Induction motor

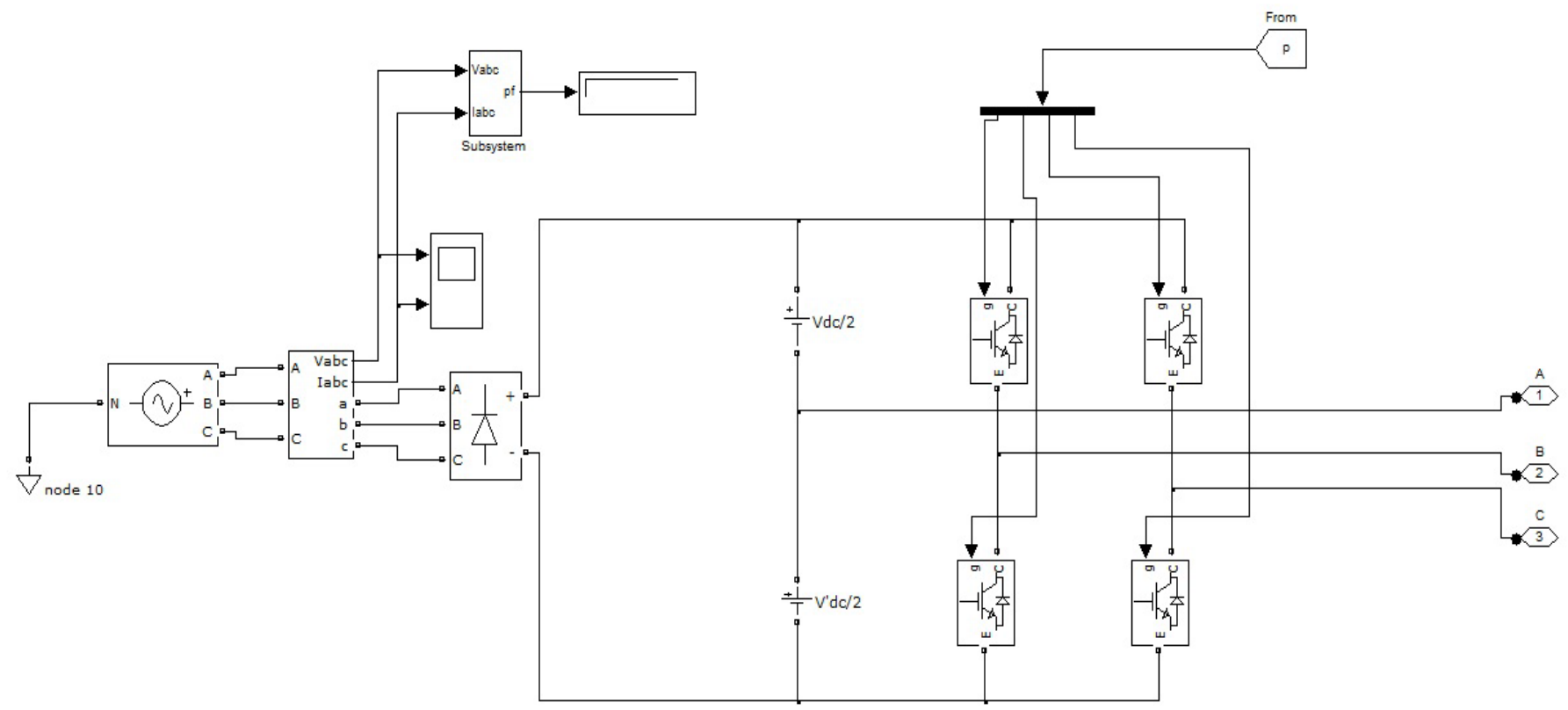

Fig 9. Subsystem for four switch inverter 


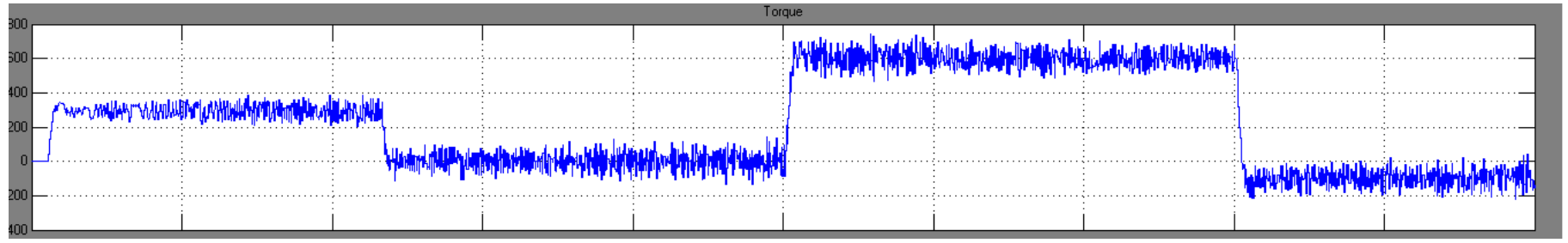

Fig 10. Torque waveform

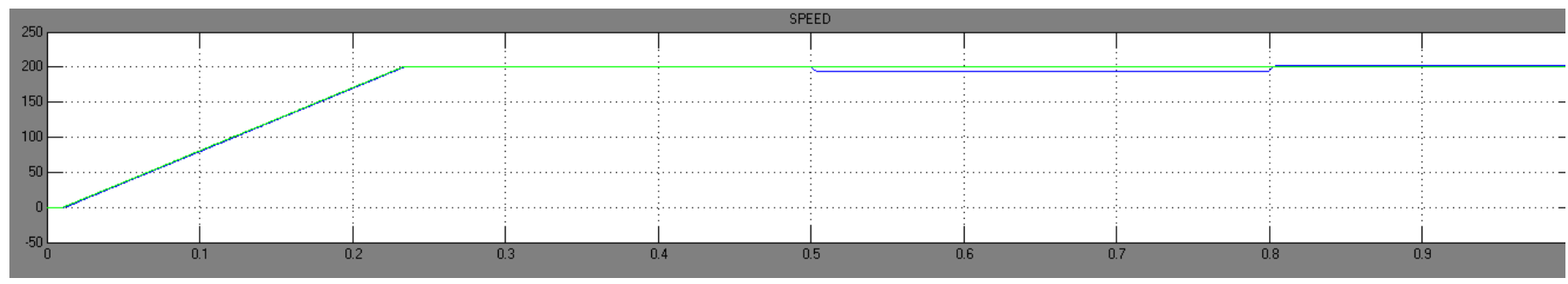

Fig 11. Speed waveform

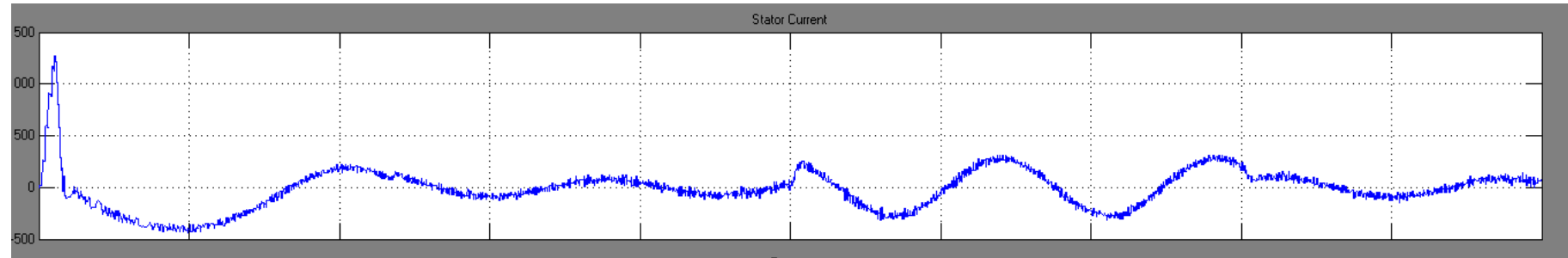

Fig 12.Stator current waveform

\section{EXPERIMENTAL SETUP}

A prototype of a Fuzzy logic DTC- FSTPI fed Induction motor is shown in Fig 13.

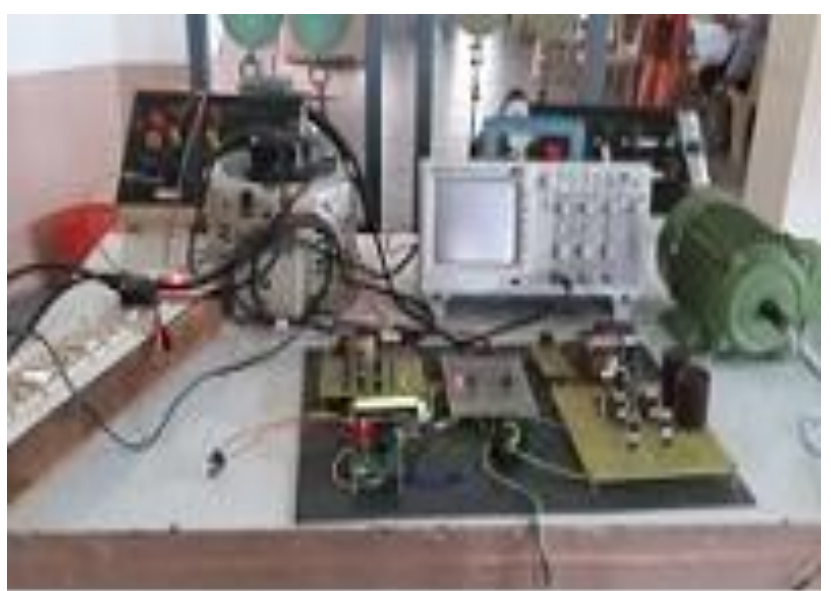

Fig 13. Experimental setup

It consists of regulated power supply, three phase inverter and driver circuit, PIC controller and a three phase induction motor. The motor has a rating of $0.5 \mathrm{HP}, 4$ pole, 1440 $\mathrm{rpm}, 50 \mathrm{~Hz}$ three phase induction motor. Fig 14 shows the gating pulse of two MOSFET connected in a phase.

Figure 9.12 shows the LCD display that shows the reference speed that we set actual speed and the current. The speed is set to $1040 \mathrm{rpm}$ and the measured speed reaches closely to the reference speed.so that the speed is controlled efficiently.

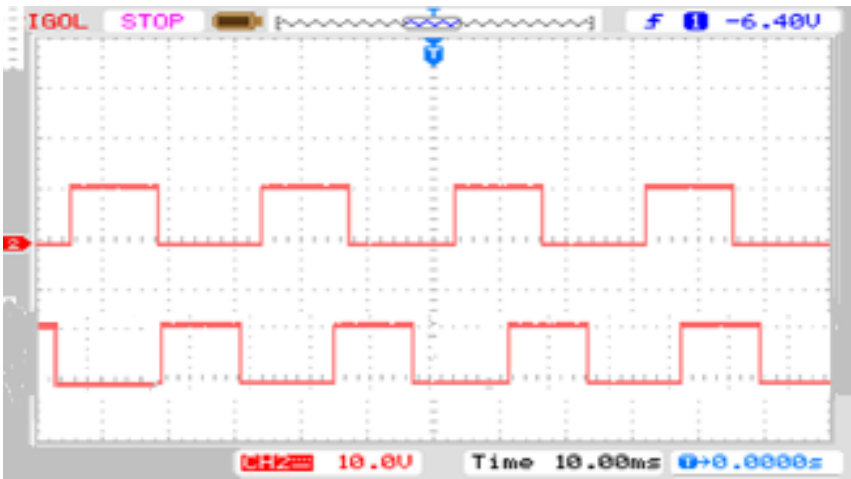

Fig 14. Gating Pulse in MOSFETS

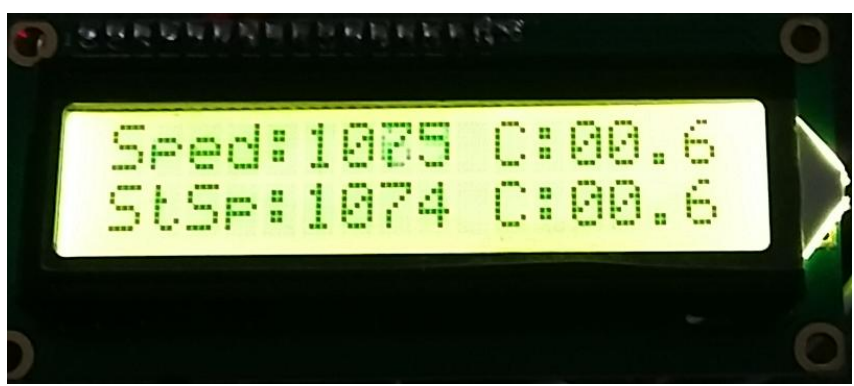

Fig 15. Speed and current in LCD display

\section{CONCLUSION}

This paper deals with the direct torque control of induction motor using fuzzy logic controller .Direct torque control (DTC) is a technique used in a three-phase motor to control the torque and eventually speed. This method involves calculating and estimating of the motor's magnetic flux and 
torque based on the measured voltage and current of the motor. This sort of control allows decoupling the flux and the torque without the need for a transformation of coordinates. To solve this problem the new approach of DTC scheme making use of fuzzy logic controller. . The analysis of speed and current waveforms are also done by using the simulation results. MATLAB/SIMULINK is used for the simulation of the proposed system .It has been observed that the torque and the stator flux ripples are reduced significantly Hardware is implemented in a $0.5 \mathrm{HP}$ induction motor and control algorithm was programmed using dsPIC16F877A.Experimental results shows that better speed control is obtained.

\section{REFERENCES}

[1]. Bassem El Badsi, Badii Bouzidi, and Ahmed Masmoudi,"DTC Scheme for a Four-Switch InverterFed Induction Motor Emulating the Six-Switch Inverter Operation",IEEE Transactions on power electronics, vol. 28, No. 7,july 2013.

[2]. M. Hafeez, M. N. Uddin "FLC-based DTC scheme to improve the dynamic performance of an IM drive,'IEEE transactions vol. 48,no.6 May 2012.

[3]. Taheri, Asghar, AbdolrezaRahmati, and ShahriyarKaboli. "Efficiency improvement in DTC of Six-phase induction machine by adaptive gradient descent of flux." Power Electronics, IEEE Transactions on 27.3 (2012): 1552-1562.

[4]. Zhang, Yongchang, and Jianguo Zhu. "Direct torque control of permanent magnet synchronous motor with reduced torque ripple and commutation frequency." Power Electronics, IEEE Transactions on 26.1 (2011): 235-248

[5]. Hong He Lee, "A new switching technique for Direct Torque Control of Induction Motor using Four-Switch Three-Phase Inverter with DC - link voltage imbalance"'Industrial Technology, Feb 2009.

[6]. M.Depenbrock, "'F. Blaabjerg, S. Freysson, H. Hansen and S. Hansen, "A new optimized space-vector modulation strategy for a component-minimized voltage source inverter"', IEEE Trans. Power Electronics, Vol. 12, NO.4, July, 1997 pp.704-714.

[7]. Takahashi, Isao, and Toshihiko Noguchi. "A new quick-response and high-efficiency control strategy of an induction motor." Industry Applications, IEEE Transactions on 5 (1986): 820-827. 